\title{
The Many Aspects of Off-Label Prescribing in Oncology
}

\author{
Anna $\mathrm{Gu}^{1, *}$ and Albert I. Wertheimer ${ }^{2}$ \\ ${ }^{1}$ Department of Pharmacy Administration, St. John's University, USA \\ ${ }^{2}$ Department of Pharmacy Practice, Temple University, USA
}

\begin{abstract}
Off-label prescribing is particularly common in oncology. While it brings abundant benefits to cancer treatment, decisions on off-label prescribing should be made with caution, due to insufficient supporting data, weak safety monitoring system, and increased health care burden. Currently, reimbursement decisions for off-label oncology are based on recommendations from four drug compendia, each of which combines data from clinical trials and/or observational studies and expert opinions. Further enhancements are expected in terms of transparency and consistency of compendia's methods of data synthesis. While the existing FDA regulations prohibit direct-to-prescriber promotion, with the exception of publication on off-label drug use, considerable leeway may be given to late-stage cancer patients. Clinical Trials for oncology off-label indication should focus on late stage cancer patients beyond firstline therapy and patient sample should have equal representations from academic and community settings. Off-label oncology clinical trials should also provide full information on conflict of interest. Given the high stakes involved in oncology treatment, future policies should strike a balance between innovation and clinical, economic, and humanistic consequences.
\end{abstract}

Keywords: Off-label drug use, cancer, health policy, FDA, healthcare reimbursement.

\section{INTRODUCTION}

Off-label drug use refers to the prescription of FDAapproved drugs for clinical indications other than those for which they received approval. In addition, off-label prescribing can occur when prescription drugs are used for populations not indicated in the label or for patients in whom the drug is contraindicated. In the United States, off-label use of approved medications is legal. Under some circumstances, off-label prescribing may become accepted by professional societies as part of the treatment guidelines. While current FDA guidelines impose strict standards for marketing of medicines, it does not regulate prescribing practices. In oncology, where many of the most expensive medications with the most severe side effects are used, there has been consistent increase in drugs used off-label in the past few decades. Based on a survey conducted in 1991, among US oncologists, one third of drugs used to treat 11 most common types of malignant tumor (including breast, colon, lung, and lymphoma) were prescribed off-label [1]. By 2005, the National Comprehensive Cancer Network (NCCN) estimated that $50 \%$ to $75 \%$ of drugs or therapeutic biologics used in cancer treatment in the US was off label [2]. More recently, Stephen et al. investigated prevalence of off-label use of oncology drugs in a community oncology Electronic Medical Records (EMR) system and found $68 \%$ of breast and $95 \%$ of lung cancer patients received drugs that were not approved by the FDA for these indications, while

*Address correspondence to this author at the Department of Pharmacy Administration and Allied Health Sciences, College of Pharmacy and Health Sciences, St. John's University, 8000 Utopia Parkway, Queens NY 11439, USA; Tel: 718-990-8263; Fax: 718-990-6316; E-mail: gus@stjohns.edu one of the bladder cancer patients and only $5 \%$ of gastric cancer patients received an FDA-approved drug [3]. Using the National Cancer Institute's Surveillance, Epidemiology and End Results (SEER) database, a study was carried out of 2,082 women over 65 with breast cancer. It was found that, of the 36 chemotherapeutic agents used to treat these patients, only $22 \%$ were FDA-approved for use in breast cancer [4]. Studies have revealed that the vast majority patients would receive at least one cancer drug prescribed off-label during the course of their treatment for cancer [5, 6].

There has been rather extensive literature documenting and discussing multiple areas surrounding this issue, as it is scattered in numerous publications over different time periods. The purpose of this report is to present a summary picture about the most debated topics in oncology off-label prescribing and shed some light on future directions.

\section{REASONS FOR ONCOLOGY OFF-LABEL DRUG USE}

The pervasive use of oncology drugs off-label arises through a number of pathways. Clinically, antineoplastic drugs are somewhat unique in that cancer, as a category of diseases, contains over 100 very different tumor types. For example, breast cancer, leukemia, and lymphoma differ in terms of histological origin, location and prognosis, although they stem from the same type of pathophysiological route of unregulated cell growth. Consequently, off-label use of oncology drugs has been widely accepted by physicians, patients and payers. There has been 
widespread off-label drug use in pediatric oncology and it is considered by many as an essential part to many treatment programs [7]. Since children are generally excluded from clinical trial, it is also reasonable to infer that physicians feel the obligation to prescribe to pediatric cancer patients for whom the label information is often insufficient to guide treatment plan [8]. Practically, after FDA approves a drug with an original indication, real-world studies may demonstrate evidence of the drug's treatment effect in a condition other than those described in the label. If the drug's patent has already expired when an additional indication is supported by post hoc data, the manufacturer has little incentive to invest time on label change $[9,10]$. This phenomenon occurs very frequently in oncology treatment, where many tumor types share the same molecular and pathophysiological pathway (thus warrants similar responses to a drug). Cancer chemotherapy often involves the use of multiple drug regimens, which may include one or more drugs not approved for the specific tumor. While the FDA generally does not approve multidrug regimens themselves, in part due to the overwhelming amount of combinations, multidrug regimens change over time as physicians explore different combinations to optimize clinical benefits and minimize side effects. Oncology off-label prescribing also occurs with varied frequency according to diverse practice settings and physician characteristics. A variety of factors have been reported to have a modulating effect on oncologists' preference toward off-label prescribing, including their knowledge, experience with patients, and influences from colleagues [11]. Besides, academic oncologists were more likely to explore and substantialize the value of off-label prescribing than their counterparts in community settings [11].

\section{BENEFITS AND BURDENS OF ONCOLOGY OFF- LABEL DRUG USE}

Off-label prescribing brings opportunities for innovation and advancement in clinical practice by adopting potentially beneficial medications supported by emerging evidence, particularly when approved regimens are lacking or have failed. In the scenario of an orphan cancer with no approved medications, offlabel regimens provide the only available treatment. For example, Intraocular lymphoma (IOL), a rare malignant form of eye cancer with ill-defined treatment, used to be treatment solely with radiation therapy. In recent years, methotrexate and Ifosfamide have been widely adopted by physicians as first-line agents after the emergence of real-world evidence $[12,13]$. Considering the lengthy FDA's drug review and approval process, off-label use may provide the only feasible way for many late-stage cancer patients to access novel therapeutic agents. Not only does offlabel prescribing brings benefits to patients, it can enhance clinicians' understanding toward a broader application of drugs to various forms of cancer [14].

At the same time, an abundance of factors warrant physicians' caution when deciding to treat their patients with off-label drugs. Unlike FDA approved indications that are supported by data from rigorous clinical trials, scientific evidence backing up off-label drug use result from case reports to observational studies with insufficient sample sizes. The largest, most carefully conducted study of outpatient prescribing patterns found that most $(73 \%)$ of medications used off-label lacked evidence of clinical efficacy [15]. Because it falls into the so-called 'gray zone' of evidence-based medicine, within which high-level evidence is difficult to obtain, lack of a rigorous approval process for off-label drug prescribing compromises drug safety. As a result, patients are particularly vulnerable to unexpected adverse events. At the time being, there is no safety monitoring tool specifically geared toward drugs used off-label. Existing pharmacoepidemiologic methods include spontaneous reports, patient registries, observational studies, clinical trials and the newly developed Sentinel System [16], which are designed for assessment of general drug safety issues and lack components related to identification of off-label uses. When new and costly drugs are used off-label, it imposes financial burdens to the society. In an era of mounting healthcare costs, off-label use in oncology, where the most expensive drugs populate, becomes a growing concern to patients and payers. Among all offlabel used biocenology agents that cost at least $\$ 1000$ per month, chemotherapeutic drugs account for $36.9 \%$, which doubled the second leading therapeutic class (enzyme deficiency, 18.5\%) [17]. Furthermore, it discourages evidence-based medical practice and subtly creates incentives for manufacturers to game the system by avoiding lengthy and costly approval process for primary indications $[10,18]$.

\section{REIMBURSEMENT FOR OFF-LABEL ONCOLOGY INDICATIONS}

Until about two decades ago, healthcare insurance generally denied claims for unlabeled drugs and biologicals. In the late 1980 s, as the amount of off-label drug prescriptions skyrocketed, it became a major policy debate whether healthcare insurance should provide reimbursement for off-label drug use [19]. As a result, in the Omnibus Budget Reconciliation Act of 
1993, congress amended Title XVIII of the Social Security Act and required federal health care programs to cover off-label indications in oncology pharmacotherapy that are deemed medically appropriate [20]. Currently, Medicare, which accounts for nearly half of the costs associated with cancer treatment nationwide, covers off-label uses of oncology chemotherapeutic regimens if they are cited as indicated by at least one of the following compendia: American Hospital Formulary Service Drug Information (AHFS-DI), United States Pharmacopoeia Drug Information for the Health Professional (USP-DI), American Medical Association Drug Evaluations (AMA-DE), and NCCN Drug \& Biologics Compendium [2, 21, 22]. Each compendium stipulates standards based on which reimbursement options are considered. For example, the NCCN Drug \& Biologics Compendium, based directly on the NCCN Clinical Practice Guidelines, specifies 4 different categories of evidence and consensus [23] for off-label oncology drug use. Category 1 recommendation is based on high-level evidence (e.g. randomized controlled trials) combined with uniform NCCN consensus; Category $2 \mathrm{~A}$ recommendation is supported by lower-level of evidence and uniform NCCN consensus; whereas Category $2 \mathrm{~B}$ recommendation derives from lower-level evidence and nonuniform NCCN consensus without major disagreement. Category 3 reflects the lowest level of recommendation, where there is a major disagreement with regard to the evidence. Typically, categories 1 and $1 \mathrm{~A}$ are deemed sufficient for reimbursement. To warrant a justifiable off-label use of chemotherapeutic agent, level 2B should be combined with support from significant peer reviewed Phase II or Phase III studies [23]. A parallel standard was adopted by Medicaid, followed by Medicare Part D for coverage of prescription drugs, as part of the Medicare Modernization Act of 2003. Although the current Social Security Act only mandates insurability of off-label anticancer drugs in federal health care programs (e.g. Medicare and Medicaid), most other payers have followed suit [22].

An expected function of drug compendia in regards to off-label drug use is to consolidate published scientific literature and to provide physicians with access to the up-to-date information that may assist in their clinical decision making in appropriate use of the drug [2]. To maintain information integrity and avoid influence from self-interested parties, some compendia set strict conflict of interests standards when choosing reviewers [21]. For example, Thomson Micromedex requires that reviewers must have less than $\$ 25,000$ of stock in the pharmaceutical industry and no employment relationship with a pharmaceutical company [2]. It is noteworthy that compendia publishers are private parties and their process of deliberation for treatment recommendations are not open to the public [21]. Based on systematic review of supporting literature for off-label indications of 14 cancer drugs, results from a recent study cast doubts on the transparency and consistency of compendia's methods to review and update evidence [22]. It remains a challenging and time-consuming task to develop an evaluating system with sound data backed by both clinical and statistical evidence to guide decision making with regard to off-label drug use in oncology. In the meantime, learning about limitations of the current drug compendia from systematic reviews and tackle the drawbacks would be a necessary step.

The extent of coverage for off-label use and the basis used for decision making vary from payer to payer. While payers of all types realize off-label drug prescribing under many circumstances, should be perceived with parallel clinical rationale to approved uses, they also recognize the potential undesirable consequences associated with it as a result of insufficient and unsubstantiated evidence [24]. When making coverage decisions for an off-label prescribing, payers should carefully assess its clinical information, economic outcomes for special patient populations and indications by exploiting drug compendia, practical guidelines, and publications in peer reviewed journals. With regard to special circumstances, there have been government regulations coercing payers to implement appeals process for consideration of exception to coverage limitations [25]. The lengthiness of appealing, however, may impose another challenge to the time sensitive nature of cancer treatment.

\section{CURRENT FDA REGULATIONS AND SUGGESTIONS}

\section{Communication of Off-Label Indications}

Although the prescription drug approval process entails rigorous evidence in efficacy and safety, and the label is specific with regard to indication and dosage, FDA has limited control over off label use once the drug is released on the market. The 2009 FDA off-label guidelines endorsed the manufacturers with flexibility to promote their drugs through distribution of journal articles, which suggested that the FDA was moving toward an even more minimal role, drew instant oppositions from the public. Rep. Henry Waxman 
(D-CA), for example, believe the policy put public health in jeopardy by creating ambiguity for drug industry to potentially bypass the FDA approval process and promote drug uses without adequate supporting data [26]. While there is a widely accepted rationale for FDA to take more active role in off-label regulation, it is conceivable that FDA relinquishes its authority in this aspect to avoid possible controversy of infringing industry's freedom of marketing their products, as long as it's not misleading [10]. While the current FDA regulation prohibits direct-to-prescriber promotion, with the exception of publications on offlabel drug use, a recent JAMA published report raised concerns that restricting off-label promotion, especially those with "truthful and not misleading" commercial speech, may hinder a physician's appropriate off-label prescribing decision and "does not directly advance government's interest in reducing unsafe drug use" [18]. On the other hand, the authors defended the current FDA restrictions on off-label promotion with two points. First, the scientific rigor and trustworthiness involved in drug review and approval process are unsurpassable by any individual prescriber. Second, allowing off-label promotion would decrease the manufacturer's incentive to conduct clinical trials for offlabel indications. We recommend that FDA to set up a hierarchical system of disease classification, in which the existing FDA approved treatment options and disease prognosis (e.g., median life expectancy) are ranked in terms of availability and poorness, respectively. Considerable leeway may be given to conditions where there is a shortened life expectancy with few FDA approved agents (e.g., late-stage cancer patients).

There has been a considerable amount of debates in the scope and depth of information which manufactures should convey in the event of unsolicited request for unapproved indications of use (off-label), both through nonpublic and public communication pathways. In response to stakeholder requests for clarification, the FDA issues draft guidance on December 27, 2011, following a citizen petition on behalf of seven prescription drug manufactures [27]. Among a number of recommendations, the draft guidance allows drug manufacturers to provide information on off-label uses in case of unsolicited request, defined as one not in any form initiated by the manufacturer or distributor itself. The draft guidance also addresses how firms should respond to requests for off-label information that occur in public communication forums, including electronic social media and internet. Due to their openness to consumers, the agency recommended that manufacturer's response "should be limited to providing [its] contact information and should not include any off-label information."

\section{Clinical Trials for Off-Label Indication}

Currently, decisions of off-label prescribing in oncology are based on several sources, including contemporary literature, drug compendia, continuing educational programs, and influence from colleagues. Even though these sources provide valuable information, there is a need for systematic guidance for clinical trials performed in the post-approval situation for decisions in off-label indications. There have been recommendations from experts in terms of trial design, patient and site recruitment, choice of comparator and outcome, and data analysis [28]. With a focus on treatment for late stage cancer patients and "pretreated patients who are beyond first-line therapy", these recommendations strengthen the importance of subpopulation of interest based on age, ethnicity, and comorbid conditions. Considering treatment patterns differ between academic and community settings, patient sample should have equal representations from the two settings. Comparators should be selected from the list of FDA-approved commonly used drugs for the proposed indication that are deemed to have the greatest risk-benefit profile. Provided as part of an effective guidance document (EGD), which was created to stipulate a framework to guide clinical trials for FDA-approved oncology drugs used off-label, the recommendations were based on far reaching discussions with stakeholders and experts and finalized through peer review, with American Society of Clinical Oncology overseeing the process. Substantial efforts from all stakeholders are needed for implementation of the guidelines and fulfill intermediate steps. For example, considering that "clinicians often do not understand HRQoL scales", it was proposed that "such scales need to be translated to more clinically relevant and meaningful tools". For another, to improve the generalizability of data, the authors urged that trials should include patients from community settings and a partnership between academic centers and communitybased sites to facilitate an infrastructure for training of community-based physicians. To achieve such objectives requires joint work from clinicians, research entities, policy makers and government organizations.

Aside from the necessity for compendia to improve its transparency in disclosure of conflict of interest (COI), it is also critical that off-label oncology clinical 
trials should provide full information in COI [29]. In a recent study, Abernethy et al. examined 69 published off-label oncology clinical trials and found a low (33\%) rate of explicit $\mathrm{COI}$ disclosure among trials. Nondisclosure of $\mathrm{COI}$ was more likely to occur in smaller scaled trials and those published in journals with lower impact factors. While a full disclosure of $\mathrm{COI}$ does not prevent $\mathrm{COI}$, it does provide useful information to clinicians and compendia publishers for decision making. Studies showed that research sponsored by pharmaceutical industry were more likely to be subject to publication bias [30]. Further, researchers who were previously involved in off-label misconduct activities are less likely to disclose their $\mathrm{COI}$ in future publications. Kesselheim and colleagues collected whistleblower complaints alleging illegal offlabel marketing from the US Department of Justice and other publicly available sources between 1996 and 2000 and identified 39 investigators who were described as having financial relationships with the defendants. Subsequently they examined their publications in the following 3 years and found that among approximately 400 articles related to the drug at issue in the whistleblower complaints, only $15 \%$ of them contained an adequate disclosure of $\mathrm{COI}$ [31].

As early as in 1999, the FDA began collecting financial disclosure information of clinical investigators and issued its initial "Guidance for Industry: Financial Disclosure by Clinical Investigators" two years later. In May 2011, FDA released a draft new version "Guidance for Clinical Investigators, Industry, and FDA Staff: Financial Disclosure by Clinical Investigators", intending to replace the former guidance [32]. Stipulating sponsor's responsibility to ensure a full disclosure of investigators' $\mathrm{COI}$ prior to their study participation and submission of market application, the new guidance was in response to Department of Health and Human Service's request that the FDA should ensure clinical trial sponsors to properly disclose investigators' financial interests and to mitigate any potential COI [33]. The draft guidance received a number of comments. For example, the Washington Legal Foundation (WLF) argued its lack of transparency on standards set for how financial information should be used submitted with marketing applications at the end of a clinical trial [33]. WLF also suggested that financial information of investigators should be reviewed and approved by the FDA prior to the start of clinical trials. It would work to FDA's advantage to establish a database for COI for investigators who were involved in previous clinical trials, including pertinent commercial or other sources of funding for the investigator or for the associated department(s) or organization(s), personal relationships, or direct academic competition. Review on the database would serve as a complementary procedure in addition to evaluation of investigator's own COI disclosure.

\section{CONCLUSIONS}

Off-label prescribing is common across therapeutic areas. However, it is critical in oncology, in which treatment options are often lacking, prognoses are dismal, and submission of different combination regimens to FDA for approval is impractical. Most offlabel oncology prescribing occurs in the absence of the scientific evidence required for FDA approval, leaving significant safety concerns to the public. In the era of radical change in healthcare policy and infrastructure, off-label prescribing in cancer treatment presents a number of challenges. Current safety monitoring tools for off-label drug use (e.g., spontaneous report, Sentinel System) are in need of enhancement with linkage between a medication and its FDA approved indications. Additional information pertaining to the specificity of adverse events should also be inherent with the review process. With the critical role of compendia in reimbursement for off-label cancer drugs, its performance in terms of timeliness and transparency needs further improvement. While clinical benefit, potential risk, and cost information strike a balance to payers who make coverage decisions, they should rely on advices from treatment guidelines and professional organizations. Given the high stakes involved in oncology treatment, it remains the biggest challenge for policy makers to bring together the competing interest of multiple stakeholders, each of whom has justifiable medical, ethical and financial perspectives about the off-label use of drugs. While future policies should minimize disincentive to innovation, it should recognize the potential clinical, economic, and humanistic burden resulted from therapies for which supportive evidence is lacking.

\section{REFERENCES}

[1] Laetz T, Silberman G. Reimbursement policies constrain the practice of oncology. JAMA 1991; 266: 2996-9. http://dx.doi.org/10.1001/jama.1991.03470210064033

[2] Soares M. "Off-label" indications for oncology drug use and drug compendia: History and current status. J Oncol Pract 2005; 1 : 102-5.

http://dx.doi.org/10.1200/JOP.1.3.102

[3] Stephen R, Knopf K, Reynolds MW, Luo W, Fraeman K. Offlabel use of oncology drugs in a community oncology EMR database. Poster presentation presented at the International Society of Pharmacoeconomics and Outcomes Research (ISPOR) Annual meeting. May 2009, Orlando FL. 
[4] MD Anderson Cancer Center. How Common Is Use of OffLabel Drugs in Breast Cancer? July 2009. Accessed February 5, 2013. Available from: http: //www.mdanderson. org/newsroom/cancer-newsline/cancer-newsline-topics/2009/ how-common-is-use-of-off-label-drugs-in-breast-cancer-.html

[5] Tabarrok A. From off-label prescribing towards a new FDA. Med Hypotheses 2009; 72: 11-3.

http://dx.doi.org/10.1016/i.mehy.2008.08.009

[6] American Society of Clinical Oncology. Reimbursement for cancer treatment: Coverage of off-label drug indications. J Clin Oncol 2006; 24: 3206-8.

http://dx.doi.org/10.1200/JCO.2006.06.8940

[7] Casali PG, Executive Committee of ESMO. The off-label use of drugs in oncology: A position paper by the European Society of Medical Oncology (ESMO). Ann Oncol 2007; 18: 1923-5.

http://dx.doi.org/10.1093/annonc/mdm517

[8] Conroy S, Newman C, Gudka. Unlicensed and off label drug use in acute lymphoblastic leukaemia and other malignancies in children. Ann Oncol 2003; 14: 42-7. http://dx.doi.org/10.1093/annonc/mdg031

[9] Epstein RS, Huang SM. They many sides of off-label prescribing. Clin Pharmacol Therap 2012; 91(5): 755-8. http://dx.doi.org/10.1038/clpt.2012.37

[10] Stafford RS. Regulating off-label drug use - rethinking the role of the FDA. N Engl J Med 2008; 358; 14; 1427-9. http://dx.doi.org/10.1056/NEJMp0802107

[11] Peppercorn J, Burstein H, Miller FG, Winer E, Joffe S. Selfreported practices and attitudes of US oncologists regarding off-protocol therapy. J Clin Oncol 2008; 26(36): 5994-6000. http://dx.doi.org/10.1200/JCO.2008.18.1420

[12] Batchelor TT, Kolak G, Ciordia R, Ciordia R, Foster CS, Henson JW. High-Dose Methotrexate for Intraocular Lymphoma. Clin Cancer Res 2003; 9: 711-5.

[13] Thiel EK, Wagner JT, Bechrakis NE, Coupland SE, Schmittel $A$, Fischer $\mathrm{L}$, et al. Ifosfamide for intraocular lymphoma. $\mathrm{J}$ Clin Oncol, 2004 ASCO Annual Meeting Proceedings (PostMeeting Edition). 2004; Vol 22, No 14S (July 15 Supplement), 1520.

[14] Abelson R, Pollack A: Medicare widens drugs it accepts for cancer. New York Times, January 27, 2009. Available from: http: //www.nytimes.com/2009/01/27/health/27cancer.html? pagewanted=all\&_r=0 Accessed on March 1 ${ }^{\text {st }}, 2013$.

[15] Eastman P. Reimbursement Policies Discourage Off-Label Drug Use. Oncol Times 2005; 27(20): 8-10. http://dx.doi.org/10.1097/01.COT.0000290944.45158.35

[16] Pan DJD. Monitoring the Safety of Medicines Used Off-Label. Clin Pharmacol Therap 2012; 91(5): 787-95. http://dx.doi.org/10.1038/clpt.2012.24

[17] Gillick MR. Controlling off-label medication use. Ann Intern Med 2009; 150: 344-7. http://dx.doi.org/10.7326/0003-4819-150-5-200903030$\underline{00108}$

[18] Kesselheim AS, Mello MM, Avorn J. FDA regulation of Offlabel drug promotion under attack. JAMA 2013; 309(5): 4456.

http://dx.doi.org/10.1001/jama.2012.207972

[19] Aronson FR, Ernest ML, Tasch M, Cusack DM. Insurance coverage for investigational therapy (letter). J Natl Cancer Inst 1990; 82: 1434.

http://dx.doi.org/10.1093/jnci/82.17.1434

[20] Pfister DG. Off-label use of oncology drugs: The need for more data and then some. J Clin Oncol 2012; 30: 584-6. http://dx.doi.org/10.1200/JCO.2011.38.5567
[21] Tillman K, Burton B, Jacques LB, Phurrough SE. Compendia and anticancer therapy under Medicare. Ann Intern Med 2009; 150(5): 348-50.

http://dx.doi.org/10.7326/0003-4819-150-5-200903030$\underline{00109}$

[22] Abernethy AP, Raman G, Balk EM, Hammond JM, Orlando LA, Wheeler JL, et al. Systematic review: reliability of compendia methods for off-label oncology indication. Ann Intern Med 2009; 150: 336-43.

http://dx.doi.org/10.7326/0003-4819-150-5-200903030$\underline{00107}$

[23] National Comprehensive Cancer Network (NCCN). The NCCN Drugs and Biologics Compendium. NCCN Compendium ${ }^{\mathrm{TM}}$. Accessed April 18, 2013. Available from http://www.nccn.org/professionals/drug compendium/content /contents.asp

[24] Radley DC, Finkelstein SN, Stafford RS. Off-label prescribing among off-based physicians. Arch Intern Med 2006; 166: 1021-6. http://dx.doi.org/10.1001/archinte.166.9.1021

[25] Teagarden JR, Dreitlein WB, Kourlas H, Nichols L. Influence of pharmacy benefit practices on off-label dispending of drugs in the United States. Clin Pharmacol Therap 2012; 91(5): 943-5. http://dx.doi.org/10.1038/clpt.2011.367

[26] American Association for Cancer Research. FDA issues new off-label guidelines. Available from: http://www.aacr.org/ home/public--media/science-policy--government-affairs/aacrcancer-policy-monitor/aacr-cancer-policy-monitor-february/ fda-issues-new-off-label-guidelines.aspx assessed on February 20, 2013.

[27] FDA: Guidance for Industry Responding to Unsolicited Requests for Off-Label Information About Prescription Drugs and Medical Devices. Available from: www.fda.gov/ downloads/Drugs/GuidanceComplianceRegulatoryInformatio n/Guidances/UCM285145.pdf Accessed February 13, 2013.

[28] Mullins CD, Montgomery R, Abernethy AP, Hussain A, Pearson SD, Tunis S. Recommendations for clinical trials of off-label drugs used to treat advanced-stage cancer. J Clin Oncol 2012; 30(6): 661-6. http://dx.doi.org/10.1200/JC0.2011.35.5198

[29] Irwin B, Hirsh BR, Samsa GP, Abernethy AP. Conflict of interest disclosure in off-label oncology clinical trials. J Oncol Pract 2012; 8(5): 298-302. http://dx.doi.org/10.1200/JOP.2011.000523

[30] Bekelman JE, Li Yi, Gross CP. Scope and impact of financial conflicts of interest in biomedical research: A systematic review. JAMA 2003; 289: 454-65. http://dx.doi.org/10.1001/jama.289.4.454

[31] Kesselheim AS, Wang B, Studdert DM, Avorn J. Conflict of Interest Reporting by Authors Involved in Promotion of OffLabel Drug Use: An Analysis of Journal Disclosures. PLoS Med 2012; 9(8): e1001280.

http://dx.doi.org/10.1371/journal.pmed.1001280

[32] FDA. Draft Guidance for Clinical Investigators, Industry, and FDA Staff: Financial Disclosure by Clinical Investigators; Available from: https://www.federalregister.gov/articles/ 2011/05/24/2011-12623/draft-guidance-for-clinicalinvestigators-industry-and-fda-staff-financial-disclosure-byclinical assessed February 12, 2013.

[33] Mansell P. FDA guidance on investigator financial disclosures needs more work, says WLF. Available from: http://www.pharmatimes.com/article/11-08-04/FDA_guidance _on_investigator_financial_disclosures_needs_more_work_s ays_WLF.aspx. Accessed February 12, 2013. 